\title{
INTERVENÇÃO PEDAGÓGICA LÚDICA EM SALA DE RECURSOS MULTIFUNCIONAIS: EXPLORANDO O CORPO HUMANO
}

Andrelissa Gorete Castanha ${ }^{1}$

Patrícia Franchi de Freitas ${ }^{2}$

Leide Daiane Mascarello do Nascimento ${ }^{3}$

\begin{abstract}
Resumo: O Programa Institucional de Bolsa de Iniciação à Docência (PIBID) tem por objetivo preparar futuros profissionais que atuarão na educação básica nas disciplinas de Ciências e Biologia.O projeto "Explorando o Corpo Humano" foi planejado, elaborado e desenvolvido como atividade de intervenção pedagógica, junto à sala de recursos multifuncionaisdo Colégio Estadual José de Anchieta. O público-alvo alcançou 4 alunos dentre os 14 que estavam matriculados na sala de recursos multifuncionais. Através de um estudo quanti-qualitativo, utilizandose da aplicação de dois questionários: antes e após a realização da aula com o jogo didático, foi possível mensurar o rendimento de cada aluno. Por conta disso, os jogos didáticos aqui desenvolvidos possibilitaram a obtenção de bons resultados na compreensão dos conteúdos pelos discentes participantes. Além disto, trouxeram uma metodologia nova, com a qual os discentes não estavam habituados e com isso, eles se mostraram muito receptivos e se sentiram muito estimulados e motivados com as novas ideias, o que proporcionou uma ação educacional muito mais efetiva.
\end{abstract}

Palavras chave: Relato de Experiência; Sistemas Biológicos; Ensino Lúdico; Ciências, Educação Especial.

\section{PLAYFUL PEDAGOGICAL INTERVENTION IN MULTIFUNCTION RESOURCE ROOM: EXPLORING DE HUMAN BODY}

\begin{abstract}
The purpose of the Institutional Program for the Initiation to Teaching (PIBID) is to prepare future professionals who will work in basic education in the subjects of Sciences and Biology. The project "Exploring the Human Body" was planned, elaborated and developed as an educational intervention activity, next to the multifunctional resource room of the José de Anchieta State College. The target audience reached 4 students out of 14 who were enrolled in the multifunction resource room. Through a quantitative-qualitative study, using two questionnaires: before and after the lesson with the didactic game, it was possible to measure the performance of each student. Because of this, the didactic games developed here allowed good results in the understanding of the contents by the participating students. In addition, they brought a new methodology, with which the students were not accustomed and with that, they were very receptive and felt very stimulated and motivated with the new ideas, which provided a much more effective educational action.
\end{abstract}

Key words: Experience Report; Biological Systems; Playful Teaching; Science, Special Education.

\section{Introdução}

O Programa Institucional de Bolsa de Iniciação à Docência (PIBID) do curso de Licenciatura em Ciências Biológicas da Universidade Tecnológica Federal do Paraná, Campus Dois Vizinhos (UTFPR-DV), tem por objetivo preparar futuros profissionais que atuarão na educação básica nas disciplinas de Ciências e Biologia. O programa vem capacitando e atendendo as demandas das escolas públicas em todo o país.

O Núcleo Regional de Educação de Dois Vizinhos atende 7 municípios: Boa Esperança do Iguaçu, Cruzeiro do Iguaçu, Dois Vizinhos, Nova Esperança do Sudoeste, Nova Prata do

\footnotetext{
${ }^{1}$ Mestranda na Universidade de São Paulo (ICB-USP), formada em Licenciatura em Ciências Biológicas pela Universidade Tecnológica Federal do Paraná, câmpus Dois Vizinhos (UTFPR-DV).

${ }^{2}$ Orientadora na Universidade Tecnológica Federal do Paraná, câmpus Dois Vizinhos (UTFPR-DV).

${ }^{3}$ Mestre em Agrossistemas na Universidade Tecnológica Federal do Paraná, CÂMPUS Dois Vizinhos (UTFPRDV).
} 
Iguaçu, Salto do Lontra e São Jorge do Oeste. São três escolas contempladas com o programa, todas localizadas no município de Dois Vizinhos.

O Programa conta com o envolvimento dos profissionais atuantes no Ensino Fundamental II e Ensino Médio, e tem como intuito colaborar com a preparação dos acadêmicos de Ciências Biológicas para que, após conclusão dos seus estudos, estejam preparados para atenderem ao Ensino Público, cientes de todos os processos e dificuldades que encontrarão dentro de uma escola e para que possam, com qualidade e dedicação, sanar os problemas enfrentados.

Dessa forma, os acadêmicos de Ciências Biológicas, também denominados "professores pibidianos", se fazem presentes nas escolas, observando e participando de todos os setores de uma escola, vivenciando as atividades e o desenvolvimento de práticas educacionais de todas as áreas do conhecimento, mas em especial de Ciências e Biologia, verificando a importância desse trabalho para o seu crescimento profissional. Prática essa que incentiva os futuros licenciados em biologia na busca de maior aperfeiçoamento profissional na área de educação básica.

Planejar, elaborar e desenvolver projetos e atividades pedagógicas junto aos Colégios Estaduais do Município de Dois Vizinhos-PR se tornou uma ferramenta de extrema importância para o aprendizado acadêmico. Nas referidas instituições ocorreram reuniões semanais com os bolsistas (professores da educação básica, denominados "supervisores"; bolsistas acadêmicos, denominados, "professores pibidianos"; professores universitários denominados "coordenadores do programa"). Os acadêmicos, em contato com as escolas, observam as demandas educacionais necessárias, as quais são analisadas pelas equipes do programa e construídos projetos e atividades a serem aplicadas no âmbito escolar. Os pibidianos de Ciências Biológicas fundamentam-se no desenvolvimento de práticas pedagógicas diversificadas junto aos professores de ciências e biologia especialmente, para fortalecimento de sua prática docente. Além disso, podem também estar compartilhando seus conhecimentos em ciências naturais com disciplinas de outras áreas do conhecimento, propondo assim, a interdisciplinaridade. A partir dessas práticas os alunos não aprendem de forma fragmentada e sim abrangendo mais áreas de estudo, o que favorece aassimilação e efetivação da aprendizagem de forma concreta. Os projetos e atividades planejadas foram/são aplicados pelos professores pibidianos como ferramenta para enriquecer a formação e capacitação acadêmica para a prática docente.

Como parte fundamental do PIBID, o projeto "Explorando o Corpo Humano" foi planejado, elaborado e desenvolvido como atividade de intervenção pedagógica, junto à sala de recursos multifuncionais do Colégio Estadual José de Anchieta (localizado no bairro Jardim Colina, em Dois Vizinhos-PR). Duas acadêmicas do PIBID, pertencentes à equipe desse colégio, 
fizeram a construção teórico-prática deste projeto. O público-alvo alcançou 4 alunos dentre os 14 que estavam matriculados na sala de recursos multifuncionais, todos com seus respectivos laudos referentes às suas dificuldades de aprendizagem. As atividades desenvolvidas na sala de recursos multifuncionais ocorreram sempre no contra turno (período vespertino).

O funcionamento da sala de recursos multifuncionais é planejado e executado em esquema de rodízio dos alunos alvo, sendo estes distribuídos e atendidos em 4 grupos de 2 a 4 alunos que alternam durante 4 tardes da semana (segundas à quintas-feiras). O projeto desenvolvido foi realizado nas tardes de terças-feiras durante 12 semanas consecutivas. Em virtude da disponibilidade, 4 alunos foram escolhidos, dentre os 14 participantes da sala de recursos multifuncionais. Os alunos escolhidos tinham idade entre 12 e 22 anos, sendo dois alunos do ensino fundamental II ( $6^{\circ}$ e $8^{\circ}$ ano), e dois do ensino médio ( $1^{\circ}$ e $3^{\circ}$ ano), constituindo assim um público muito heterogêneo.

Como objetivos, buscou-se:

$\checkmark$ Contribuir com o aprendizado sobre os sistemas biológicos que constituem o corpo humano pelos estudantes participantes da sala de recursos multifuncionais;

$\checkmark$ Proporcionar uma metodologia de ensino diferenciada, buscando a educação formal inclusiva, que considera as necessidades específicas de cada aluno, de acordo com suas respectivas dificuldades de aprendizagem;

$\checkmark$ Enriquecer e diversificar as formas de ensinar, através do incentivo e aprimoramento da utilização de atividades pedagógicas lúdicas;

$\checkmark$ Promover a socialização participativa entre os estudantes envolvidos.

Esse trabalho fundamentou-se em aproximar os acadêmicos do curso de licenciatura à prática docente através de um processo diferenciado de ensino, desmistificando-se a ideia de que $\mathrm{o}$ ato de ensinar ocorre de forma homogênea. Com isso, procurou-se trazer à tona uma abordagem didática notória que contribuirá significativamente para os estudos relacionados à educação inclusiva nas escolas públicas, colaborando também no aprimoramento de ferramentas para o trabalho docente, no que se refere à diversificação das metodologias didático pedagógicas lúdicas (ANTUNES \&SABÓIA MORAES, 2010) relacionadas ao estudo do corpo humano.

O projeto foi desenvolvido considerando: 1) as Diretrizes da Educação Básica do Estado do Paraná, no que se refere à Educação Especial e ensino de Ciências e Biologia; 2) a Política Nacional de Educação Especial na Perspectiva da Educação Inclusiva, proposta pelo Ministério da Educação; 3) as observações realizadas em aulas na sala de recursos multifuncionais do 
colégio e o uso de jogos didáticos no processo de ensino-aprendizagem, bem como fundamentalmente às necessidades específicas dos alunos participantes.

O presente artigo traz um relato de experiência da aplicação de metodologias diferenciadas em sala de recursos multifuncionais para alunos do ensino fundamental e médio, visando construir jogos didáticos a fim de estimular o interesse dos alunos no estudo dos sistemas biológicos do corpo humano.

Para produzir dados analisáveis realizamos um estudo quanti-qualitativo, aplicando dois questionários: um antes e um após a realização da aula com o jogo didático, a fim de mensurar o rendimento de cada aluno. Portanto, pelos dados gerados conserva-se a concepção de que o uso de diferentes jogos pode proporcionar um efeito benéfico para a aprendizagem, de acordo com os resultados obtidos através do estudo quanti-qualitativo.

Ressaltamos ainda, que este projeto foi apoiado e assistido pelos seguintes profissionais do colégio: pedagoga responsável, supervisora local do PIBID biologia e professora regente da sala de recursos multifuncionais. Com isso, houveum ótimo envolvimento do corpo docente na realização de práticas desenvolvidas junto aos alunos da sala de recursos.

\section{O Ensino-Aprendizagem}

Segundo as Diretrizes Curriculares da Educação Básica (2013), "um sujeito é fruto de seu tempo histórico, das relações sociais em que está inserido, mas é, também, um ser singular, que atua no mundo a partir do modo como o compreende e como dele lhe é possível participar". Portanto, o profissional atuante na área de ensino, deve compreender que cada indivíduo possui peculiaridades para a construção de sua própria história, independente da sua condição de aprendizagem e do tempo necessário para aprender um novo conceito. É importante levar em conta que a instrução, para o aluno, atua como formadora de um cidadão crítico e consciente e que, como indivíduos não somos formados apenas para o mercado de trabalho, como muitos propõem para o processo de educação brasileira.

Além do mais podemos inferir, conforme Lakomy (2014), "a aprendizagem ocorre quando, por meio de uma experiência, mudamos nosso conhecimento anterior a respeito de uma ideia, comportamento ou conceito". Isso se deve a um importante recurso que vem recentemente sendo discutido na área da medicina, termo intitulado plasticidade cerebral. Conforme a explicação de Leal e Nogueira (2012), esse termo foi muito discutido na década de 1950, pelos médicos que acreditam que quando na situação de perda neural e de conexões sinápticas, "o tecido cerebral não se regenerava e que o cérebro já possuía uma programação genética definida (2012, p. 92)”. Já em um contexto mais atual Muszkat (2005, p. 29) afirmou que: 
"A plasticidade cerebral pode ser definida como uma mudança adaptativa na estrutura e função do sistema nervoso, que ocorre em qualquer fase de ontogenia, como função de interações com o meio ambiente interno e externo, ou ainda como resultantes de lesões que afetam o ambiente neural (MUSZKAT apud LEAL e NOGUEIRA (2012, p. 102)”.

A fim de criar uma modalidade de prática docente que busca construir um ensino mais inclusivo e humano foi instituída a educação especial. Pois conforme Silva (2012) "a educação especial é uma área de conhecimento e também uma modalidade de ensino que tem como objetivo o desenvolvimento de práticas e estratégias pedagógicas voltadas para os alunos com necessidades educacionais especiais”. Ela é responsável pelo trabalho de educar e formar cidadãos cujo sistema tradicional lida de forma indevida e incoerente não atendendo as particularidades de cada indivíduo, mas sim as exigências propostas para todos os discentes de forma homogênea e muitas vezes exclusiva.

Aplicando-se de uma das teorias de aprendizagem temos a que busca a construção da afetividade proposta pelo médico, filósofo e político francês Henri Wallon. Segundo Lakomy (2014) temos que "a afetividade dá lugar ao desenvolvimento cognitivo quando a criança começa a construir a realidade por meio do que Wallon (2005) chama de inteligência prática ou das situações".

\section{Legislação X a Prática Docente}

A educação pública em nosso país vem desde a década de 1990 alterando suas políticas educacionais. Atualmente, brasileiros com necessidades físicas e intelectuais têm direito de estarem inseridos em salas comuns com matrículas garantidas por lei em escolas públicas de Educação Básica Regular, e com direito de atendimento especializado de acordo com a deficiência apresentada (BRASIL, 2007; 2011).

O Art. 27 da Lei № 13.146/2015 a qual estabelece a Lei Brasileira de Inclusão da Pessoa com Deficiência (Estatuto da Pessoa com Deficiência), define a educação como:

“[...] direito da pessoa com deficiência, assegurados sistema educacional inclusivo em todos os níveis e aprendizado ao longo de toda a vida, de forma a alcançar o máximo desenvolvimento possível de seus talentos e habilidades físicas, sensoriais, intelectuais e sociais, segundo suas características, interesses e necessidades de aprendizagem."

Quando nos referimos à prática docente devemos levar em consideração que a mediação pedagógica deve ser livre de preconceitos e inseguranças. Na educação e, em especial na inclusiva, a relação entre professor-professor, professor-aluno e aluno-aluno são de extrema importância. A atitude e o comportamento do professor frente às expectativas dos seus alunos fazem toda a diferença no processo de ensino aprendizagem. O professor deve demonstrar 
interesse no que está ensinando, ser colaborativo e facilitador para que seus alunos consigam buscar o que lhe traz interesse para que consigam atingirem seus objetivos.

Pinheiro \& Mascaro (2016) reafirmam que, a concretização da Lei só será possível quando os professores obtenham clareza sobre o processo de inclusão. Procurem compreender a importância para os alunos, sobre o atendimento psicopedagógico e psicomotricidade, terapia ocupacional e fisioterapia das escolas com Educação Especial, bem como, o papel da Inclusão Escolar em escolas de Educação Básica. Assim, alcançaremos um ensino colaborativo frente aos desafios escolares.

Segundo Schlunzen et al (2016), foi observado que projetos de ensino, extensão, pesquisa e formação de professores demonstrou-se significativos no processo de acessibilidade e resolução de problemas de compreensão e atuação na educação inclusiva. Portanto, torna-se evidente a importância da busca pelo conhecimento e aperfeiçoamento profissional frente às demandas escolares, para um ensino de qualidade e comprometimento.

\section{A Aplicação do Projeto}

Durante o período de doze semanas consecutivas, foram ministradas doze aulas demonstrativo-práticas na sala de recursos multifuncionais, contemplando o período de três horas aula para cada encontro. Assim, a programação das aulas foi planejada com a previsão das seguintes atividades:

I- Em oito desses encontros foram abordados os temas: Sistema locomotor, digestório, respiratório, circulatório, urinário, reprodutor, sentidos e nervoso. Para cada um dos temas foi proposta, a seguinte sequência de atividades:

$1^{\circ}$ ) Aplicação de um pré-questionário, correspondente ao assunto da aula, buscando explorar o conhecimento prévio dos alunos;

$2^{\circ}$ ) Explanação do conteúdo a ser trabalhado na aula;

$3^{\circ}$ ) Aplicação de um jogo sobre o sistema abordado, com intuito de relacionar teoria e prática;

$4^{\circ}$ ) Aplicação do pós-questionário, idêntico ao pré-questinário o qual também foi respondido pelos alunos.

II- Em quatro dos doze encontros foram desenvolvidos um momento de introdução e três momentos de revisão dos conteúdos. Através de dinâmicas e momentos de retomadas de conteúdo, os alunos puderam refletir sobre a relação do exposto ao seu cotidiano, resinificando o processo de aprendizagem.

Desse modo, procurou-se organizar os 12 encontros conforme descritos a seguir: 
No primeiro encontro foi realizada a construção um modelo de corpo humano, com materiais recicláveis, ilustrando cada uma de suas partes (órgãos, estruturas), explanando suas respectivas funções e localizações, bem como indicando a qual sistema pertencem. O modelo foi elaborado com os seguintes sistemas: Sistema Locomotor, Digestório, Respiratório, Circulatório (Sanguíneo e Linfático), Urinário, Reprodutor (Masculino e Feminino), Sentidos e Nervoso.

Do segundo ao quarto encontro foram abordados individualmente três conteúdos; sistemas locomotor, digestório e respiratório, respectivamente. No quinto encontro foi realizada a revisão dos assuntos trabalhados durante o segundo, terceiro e quarto encontro. Esta revisão consistiu da aplicação de um jogo de tabuleiro, intitulado “Quem Sou Eu?” (que será explanado adiante).

Do sexto ao oitavo encontro foram abordados, na seguinte ordem, os conteúdos do sistema circulatório (sanguíneo e linfático), urinário e reprodutor (feminino e masculino), respectivamente. No nono encontro, assim como no quinto, foi realizada uma aula de revisão em que os assuntos revisados foram os mesmos do sexto ao oitavo encontro.

Nos décimo e décimo primeiro encontros foram abordados os assuntos: órgãos dos sentidos e sistema nervoso. Nestes dois penúltimos encontros não foram aplicados jogos didáticos, mas sim aulas práticas.

E para finalizar, o décimo segundo e último encontro consistiu-se na revisão e reaplicação do jogo “Quem Sou Eu?”, porém desta vez incluindo todos os conteúdos ministrados nos onze primeiros encontros.

\section{Avaliação Qualitativa}

Como metodologia avaliativa, foi adotada a seguinte abordagem: a aplicação de um questionário em dois momentos distintos, um anterior a realização da aula/aplicação do jogo didático (para verificação do conhecimento prévio dos alunos) - questionário pré, e outro (idêntico ao primeiro) após - questionário pós. Ambos os questionários respondidos pelos alunos foram, então, comparados para a verificação do aprendizado.

Desta forma, oquestionário foi o principal instrumento avaliativo para a análise do ganho no aprendizado dos alunos. Pois, buscando contemplar a importância do uso de questionários, Fachin (2006, p. 161) afirma que "a vantagem do questionário é que ele é visto como um instrumento de coleta de informações relativamente acessível, se comparado aos demais".

Outros elementos importantes também foram considerados como parte das análises de dados. Além do trabalho comparativo entre os questionários, foram realizados e analisados os registros diários do envolvimento individual dos alunos nas atividades desenvolvidas durante as 
aulas, a aplicação de jogos, bem como as respostas orais obtidas durante a aplicação do jogo e aulas.

\section{Construção dos Jogos e Aulas Práticas}

Os jogos da memória foram construídos com o intuito de abordar os sistemas locomotor e reprodutor, tanto masculino quanto o feminino. Ambos seguiram o método tradicional de construção para jogos de memória no qual, cada participante poderia retirar do conjunto de cartas, embaralhadas e viradas para baixo, duas cartas a fim de achar o par equivalente. Entretanto, o par não consistia de duas imagens semelhantes, mas sim de informações que se complementavam, no caso a imagem de um órgão ou estrutura e seu respectivo nome ou função. Ao final do jogo, o aluno que obtivesse mais pares de cartas seria o vencedor.

Os jogos de bingo foram trabalhados com os sistemas digestório e circulatório, tanto sanguíneo quanto o linfático. Ambos foram realizados conforme o método tradicional para um jogo de bingo. Primeiramente cada aluno recebia uma cartela, na qual constavam os nomes das estruturas presentes nesses sistemas abordados, ao invés de números. Sequencialmente, cada aluno retirava aleatoriamente uma carta para o colega seguinte responder. A resposta poderia estar ou não na cartela, devendo preenchê-la com algum material definido. Os alunos participantes utilizaram pedacinhos de canudinhos para a realização desse preenchimento. $\mathrm{O}$ aluno que completasse a cartela primeiro, seria o vencedor.

Os jogos de dominó foram trabalhados com os sistemas respiratório e urinário. Os dois jogos seguiram o método tradicional do jogo de dominó. Primeiramente foram distribuídas peças de forma igualitária para todos os participantes. Essas peças eram colocadas no centro e cada aluno deveria completar com a imagem ou os dados correspondentes, de forma que sequencialmente todos participassem. Por fim, o aluno vencedor era aquele que colocasse todas as suas peças no jogo, ou seja, terminasse primeiro.

O jogo "Quem Sou Eu?" foi criado na forma de um tabuleiro, com o objetivo de revisar os sistemas estudados. O jogo foi aplicado em três momentos distintos: Nos quinto e nono encontros com o objetivo de revisar três conteúdos trabalhados previamente a cada um desses encontros, e no décimo segundo e último encontro com o propósito de finalizar as atividades abordando todos os conteúdos contemplados no projeto. O jogo foi aplicado da seguinte maneira: o aluno que sorteasse o maior número no dado começaria a rodada e assim, sucessivamente, entre todos os integrantes. Com isso, o primeiro aluno jogava o dado enquanto o aluno anterior ficava com a responsabilidade de retirar uma carta para perguntar ao primeiro, para que este não visualizasse a resposta e pudesse articular uma ideia própria. Essas questões 
eram referentes a um sistema dentre os estudados, e foi contabilizado o número de tentativas de respostas para cada aluno e cada questão. Aquele que acertasse a questão avançaria duas casas, enquanto que quando errasse deveria voltar uma casa. Além disso, existia no tabuleiro a casa "Pista", a qual visava uma chance extra do aluno responder à questão sob o auxílio do professor. Desta forma, o professor poderia colaborar com dicas sobre o assunto para o participante que caísse nessa casa. O aluno que acertou mais questões utilizando a menor quantidade de tentativas, ao longo das rodadas solicitadas foi o vencedor.

As aulas práticas desenvolvidas foram aplicadas com os dois últimos conteúdos do projeto, ou seja, órgãos dos sentidos e sistema nervoso. Ambas as aulas intercalaram momentos de aula expositiva dialogada com as atividades práticas desenvolvidas.

A aula sobre sentidos foi dividida em cinco momentos, dentro dos quais foram abordados individualmente os cinco órgãos dos sentidos: visão, audição, tato, olfato e paladar. Sequencialmente a cada um desses momentos houve a realização de uma atividade prática conforme a relação abaixo:

1- Visão: descrição e identificação de objetos;

2- Audição: definição de sons de objetos e animais;

3- Tato: identificação de materiais presentes dentro de uma caixa ("a caixa dos sentidos");

4- Olfato: reconhecimento de odores;

5-Paladar: reconhecimento de sabores.

$\mathrm{Na}$ aula destinada à explicação do conteúdo referente ao sistema nervoso, foi abordada a classificação do sistema nervoso e o seu funcionamento como um todo, bem como a célula principal, o neurônio. Após o momento teórico, foi aplicada uma atividade prática, com um desenho a ser colorido e preenchido com a indicação das diferentes áreas e funções do encéfalo humano.

\section{Análise Quantitativa}

A análise quantitativa dos questionários aplicados foi realizada considerando três aspectos: 1) comparativo entre os oito sistemas trabalhados; 2) aplicação do jogo "Quem Sou Eu?” em seus três momentos e, por fim, 3) o número de acertos na aplicação do último jogo.

A análise quantitativa do aproveitamento dos alunos foi realizada através do número de acertos nos questionários pré e pós comparativamente em cada um dos doze encontros doprojeto.

Através da análise dos acertos obtidos nos questionários pré e pós que contemplaram cada um dos oito sistemas estudados (gráfico 1), foi possível verificar que todas as aulas 
contribuiram de maneira positiva para o aprimoramento do conhecimento por parte dos alunos. O maior aproveitamento registrado foi nas aulas sobre o sistema locomotor e sistema nervoso, visto que, a diferença entre o número de acertos entre os questionários pré e pós foi de 32,27\% e $33,37 \%$, respectivamente. O aproveitamento de $100 \%$ no questionário pós aula e jogo foi registrado para os sistemas digestório, circulatório, urinário e reprodutor.

Gráfico 1: Quantificação do aproveitamento dos alunos nos questionários, comparando a aplicação pré e pós dos mesmo, em relação aos sistemas aplicados.

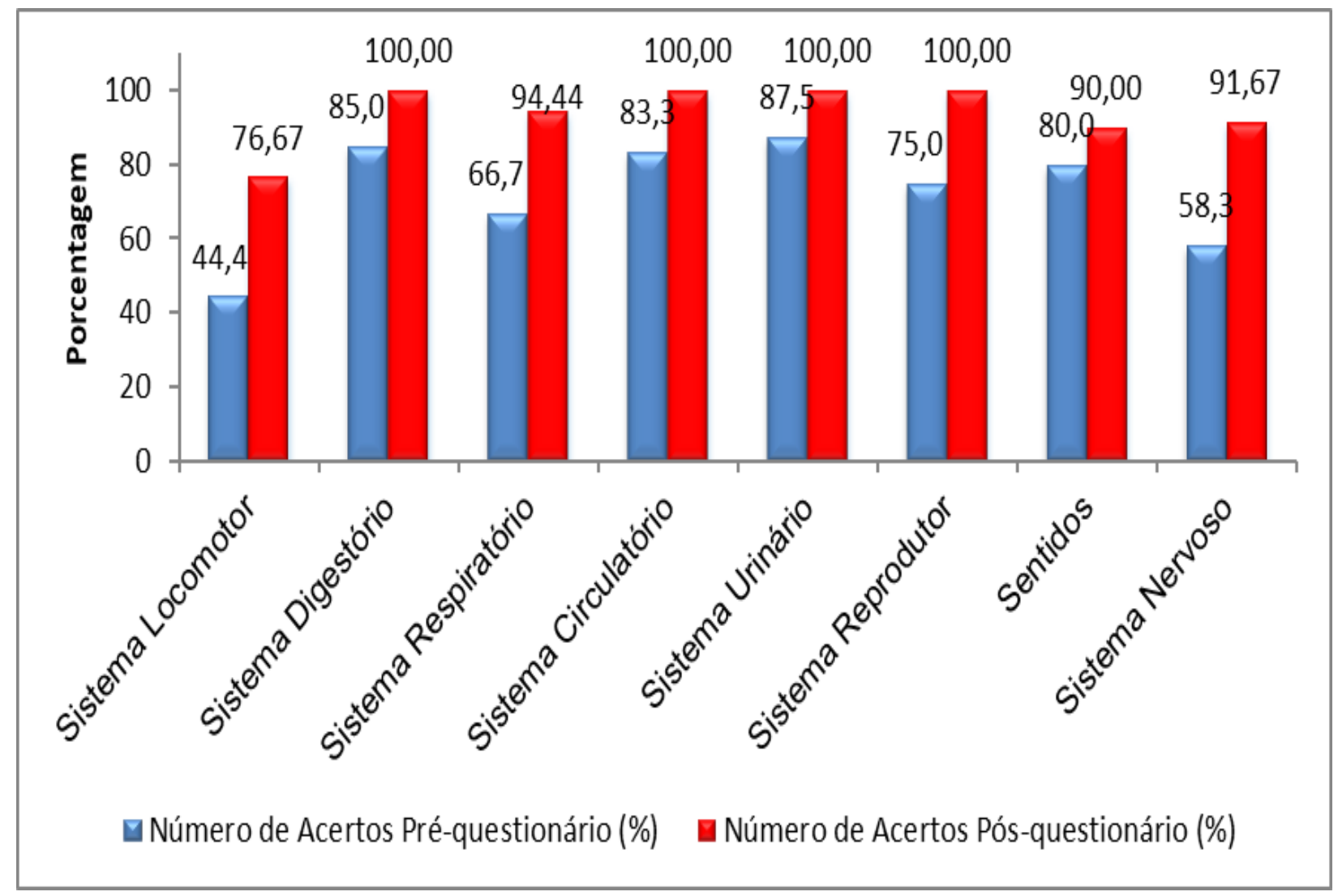

Fonte: Dados da pesquisa organizados pelas autoras.

O jogo "Quem Sou Eu?" foi desenvolvido com o objetivo de revisar os conteúdos ministrados. O jogo foi aplicado três vezes durante o projeto. No primeiro momento (jogo 1), os sistemas revisados foram: locomotor, digestório e respiratório. No segundo momento (jogo 2), foram revisados os sistemas circulatório (sanguíneo e linfático), urinário e reprodutor (masculino e feminino) e por fim (jogo 3), todos esses sistemas anteriormente citados foram trabalhados somando-se ao dos sentidos e do sistema nervoso.

A partir da análise do gráfico 2 , foi possível observar que o maior rendimento por parte dos alunos foi na aplicação do jogo 3, com uma diferença no número de acertos de 33,3\% entre 
os questionários pré e pós. Para os jogos 1 e 2, o aproveitamento registrado foi de 22,2\% e $16,7 \%$, respectivamente. Vale ressaltar que no jogo 1 houve $100 \%$ de acertos no questionário pós.

Gráfico 2: Quantificação dos questionários referentes aos jogos de revisão, utilizando como recurso o jogo "Quem Sou Eu?

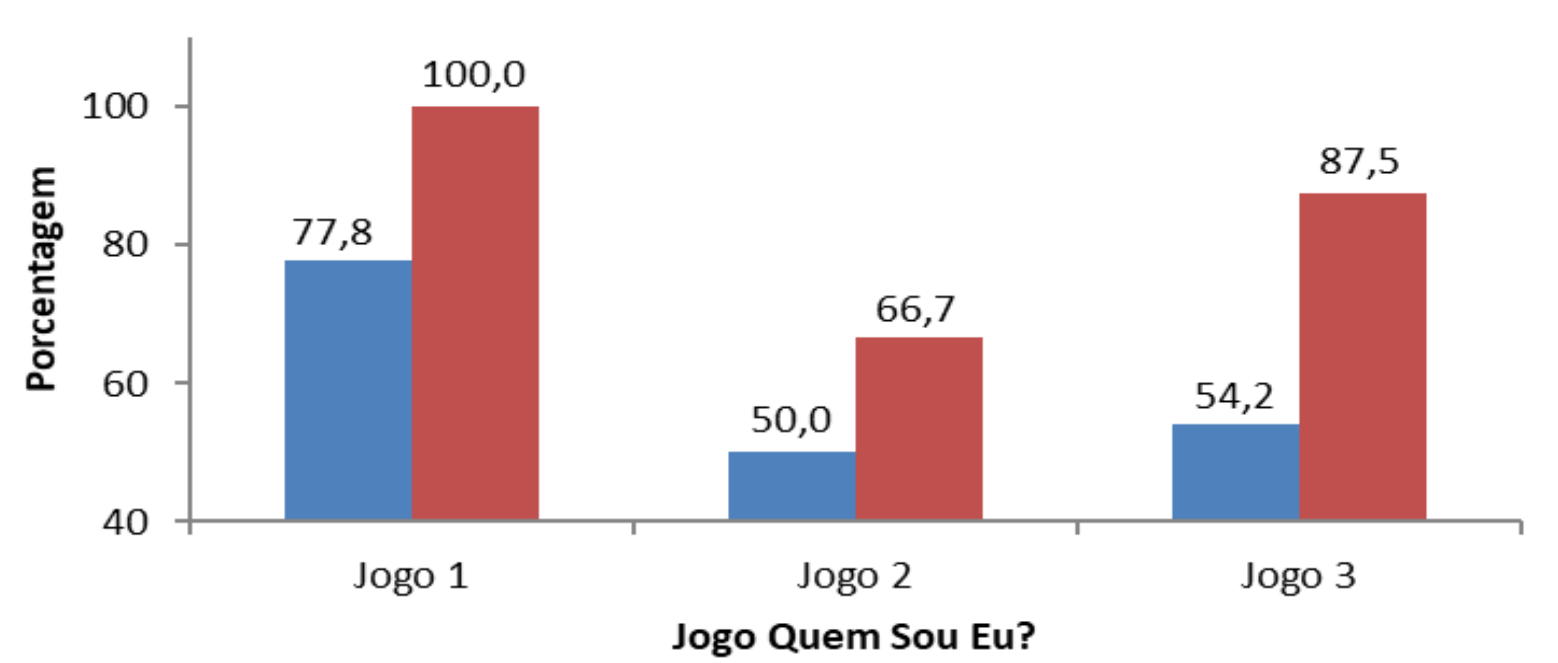

- Número de Acertos Pré-questionário (\%)

— Número de Acertos Pós-questionário (\%)

Fonte: Dados da pesquisa organizados pelas autoras.

O gráfico 3 demonstrou que os quatro alunos participantes conseguiram acertar na primeira tentativa, dentre as oito rodadas, ao menos cinco vezes e, que apenas o terceiro aluno necessitou de três tentativas para responder a questão solicitada.

Considerando que o número de tentativas de respostas está correlacionado ao conhecimento adquirido pelo aluno, temos um resultado positivo ao mencionar que o aluno compreendeu a temática proposta no jogo, além de que a explanação teórica da aula foi assimilada com sucesso. 
Gráfico 3: Quantificação do jogo de revisão “Quem Sou Eu?”.

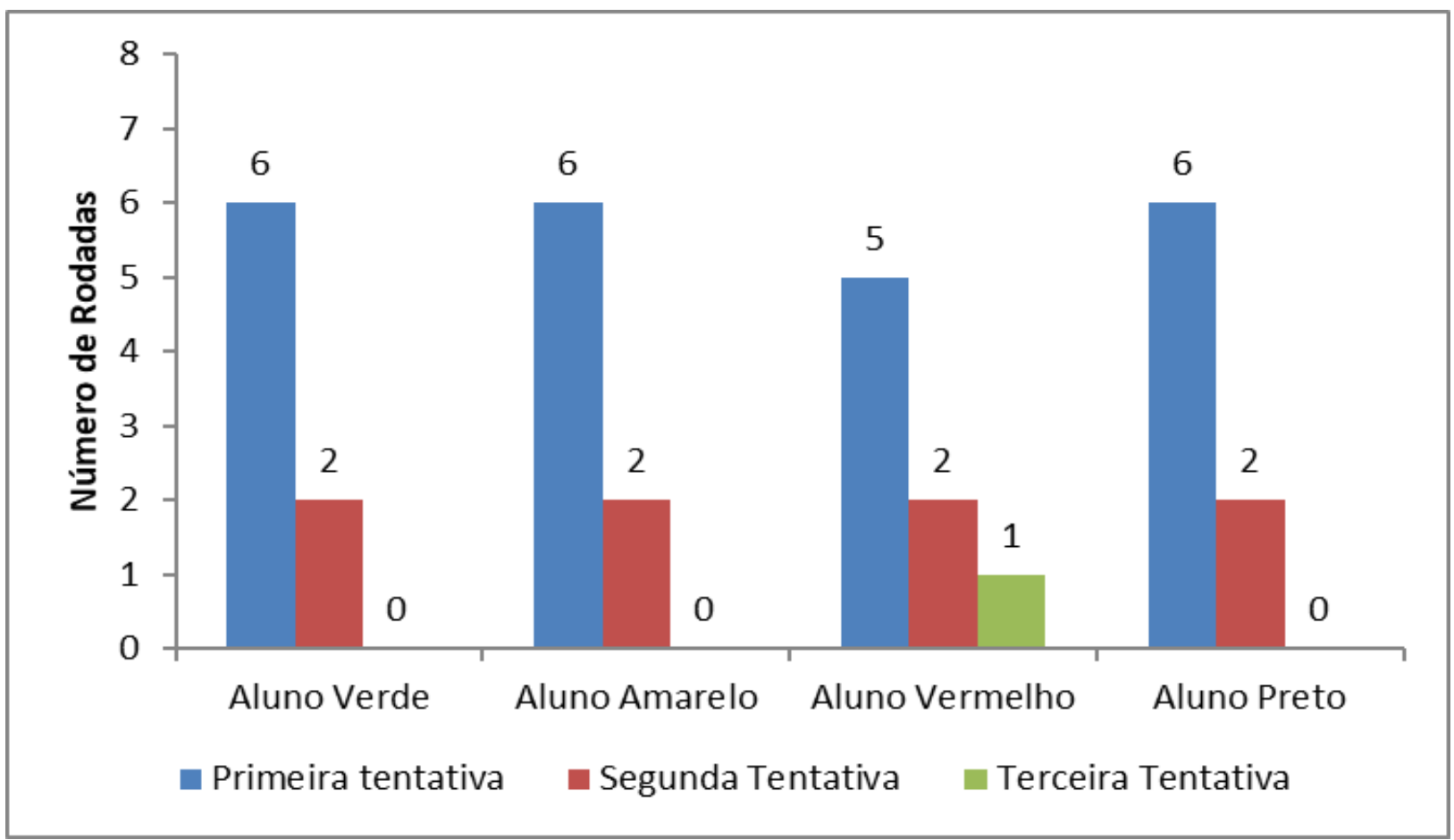

Fonte: Dados da pesquisa organizados pelas autoras.

Comparado com as diferentes abordagens descritas na literatura relacionadas à aplicação de atividades lúdicas na educação especial, o presente trabalho representa uma versão totalmente inovadora de ensino, pois o conteúdo dos sistemas biológicos do corpo humano sempre proporciona vários momentos de dúvidas entre os alunos e, principalmente dentre aqueles com dificuldades de aprendizagem há um número ainda maior de indagações. Por conta disso, os jogos didáticos aqui desenvolvidos possibilitaram a obtenção de bons resultados na compreensão dos conteúdos pelos discentes participantes. Além disto, trouxeram uma metodologia nova, com a qual os discentes não estavam habituados e com isso, eles se mostraram muito receptivos e se sentiram muito estimulados e motivados com as novas ideias, o que proporcionou uma ação educacional muito mais efetiva.

\section{Conclusão}

O trabalho realizado proporcionou a aplicação de várias práticas pedagógicas positivas ao processo de ensino e aprendizagem. Essas práticas possibilitaram a constatação de que, primeiramente a educação deve sempre ser valorizada e, também que existem variadas formas de proporcionar o aumento do conhecimento a todos. Além disso, na educação especial deve-se aprimorar ainda mais o uso de técnicas e metodologias diferenciadas visando atingir aqueles que 
normalmente são esquecidos por conta de suas limitações, mais adequadamente chamadas de dificuldades de aprendizagem.

A partir da realização desse trabalho concluiu-se que a metodologia tradicional de ensino pode até ser mais "fácil" de ser trabalhada, mas que a realização de atividades lúdicas diferenciadas, em especial com a utilização de jogos didáticos, proporcionou um efeito renovador na educação possibilitando o acréscimo de conhecimento por parte dos alunos. Estes se sentiram mais valorizados e buscaram aumentar seu conhecimento e, com isso proporcionaram um ambiente mais interativo e dinâmico.

A construção dos jogos possibilitou a realização de inúmeras atividades e foi possível concluir que os alunos possuem um conhecimento prévio, que pode ser aproveitado e ampliado, e que quando atrelado ao lúdico tem-se um rendimento quantitativo expressivo.

\section{Referências}

ANTUNES, A. M.; SABÓIA-MORAIS, S. M. T. O jogo educação e saúde: uma proposta de mediação pedagógica no ensino de ciências. Experiências em Ensino de Ciências. Goiânia, V5(2), pp. 55-70, 2010.

BRASIL. Lei 9394, de 20 de dezembro de 1996. Estabelece as diretrizes e bases da educação nacional. Apresentação de Carlos Roberto Jamil Cury. 9ª ed. Rio de Janeiro: DP\&A, 2005.

BRASIL. MEC/SEESP. Política nacional de educação especial na perspectiva da educação inclusiva. Brasília: MECSECADI, 2008, 15 p. Disponível em: <http://peei.mec.gov.br/arquivos/politica_nacional_educacao_especial.pdf>. Acesso em: 21 mar. 2016.

BRASIL.Lei No 13.146, DE 6 DE JULHO DE 2015. Estatuto da Pessoa com Deficiência. Lei Brasileira de Inclusão da Pessoa com Deficiência. Disponível em: <http://www.planalto.gov.br/ccivil_03/_ato2015-2018/2015/lei/113146.htm>. Acesso em 15 jan. 2018.

LAKOMY, A. M. Teorias cognitivas da aprendizagem. 1 ed. Curitiba: InterSaberes, 2014.

LEAL, D. Dificuldades de aprendizagem: um olhar psicopedagógico. 1 ed. Curitiba: InterSaberes, 2012.

PINHEIRO, V. C. da S.; CARVALHO, C. A. de A. A Bidociência como uma proposta Inclusiva. JournalofResearch in SpecialEducationalNeeds. Rio de Janeiro, V. 16, $\mathrm{n}^{\circ}$ 1, pp 37-40, 2016.

SCHLÜNZEN, E. T. M; SCHLÜNZEN K. J.; SANTOS, D. A. do N. dos S. Ambientes potencializadores para a Inclusão. JournalofResearch in SpecialEducationalNeeds. São Paulo, V. 16, $\mathrm{n}^{\circ} 1$, pp 140-144, 2016.

SILVA, A. M. da. Educação especial e inclusão escolar: história e fundamentos. 1 ed. Curitiba: InterSaberes, 2012.

PARANÁ. Secretaria de Estado da Educação do Paraná- Diretrizes Curriculares da Educação Básica. 2013. Disponível em: http://www.educadores.diaadia.pr.gov.br/arquivos/File/diretrizes/dce_bio.pdf. Acesso: $30 / 05 / 2017$. 